\title{
Adolescent obesity and maternal and paternal sensitivity and monitoring
}

\author{
R. NEAL DAVIS ${ }^{1}$, JACQUELINE ASHBA ${ }^{2}$, DANIELLE P. APPUGLIESE ${ }^{2}$, NIKO KACIROTI $^{3}$, \\ ROBERT F. CORWYN ${ }^{4}$, ROBERT H. BRADLEY 5 \& JULIE C. LUMENG ${ }^{3,6}$ \\ ${ }^{1}$ Child Health and Evaluation Research (CHEAR) Unit, Division of General Pediatrics, University of Michigan, \\ Ann Arbor, Michigan, ${ }^{2}$ Data Coordinating Center, Boston University School of Public Health, Boston, Massachusetts, \\ ${ }^{3}$ Center for Human Growth and Development, University of Michigan, Ann Arbor, Michigan, ${ }^{4}$ Department of Psychology, \\ University of Arkansas at Little Rock, Little Rock, Arkansas, ${ }^{5}$ Family \& Human Dynamics Research Institute, Arizona \\ State University, Tempe, Arizona, ${ }^{6}$ Department of Pediatrics and Communicable Diseases, University of Michigan, \\ Ann Arbor, Michigan, USA
}

\begin{abstract}
Objective. To determine if adolescent obesity is associated with parenting characterized by lower sensitivity and lower monitoring of adolescent activities. Methods. We used data from 744 adolescents in the National Institute of Child Health and Human Development Study of Early Child Care and Youth Development. Height and weight were measured at age $15 \frac{1}{2}$ years and obesity defined as body mass index $\geq 95$ th percentile for age and sex. Maternal and paternal sensitivity were assessed by direct observation of a parent-adolescent interaction task. Maternal and paternal monitoring were assessed by parent report. Lower sensitivity and lower monitoring were each defined as the lowest quartiles. Two separate multivariate logistic regression models were created to evaluate, individually for mothers and fathers, associations of sensitivity and monitoring with adolescent obesity, controlling for adolescent sex and race, family income-to-needs ratio, and parental obesity. Results. Fourteen percent of the adolescents were obese. Lower sensitivity was associated with adolescent obesity in the maternal parenting model (adjusted odds ratio [AOR] 2.36, 95\% confidence interval [CI] 1.44-3.86, n= 709), but not paternal parenting model (AOR $=0.79,95 \%$ CI $0.38-1.63, n=460$ ). Neither maternal nor paternal monitoring was associated with adolescent obesity ( $\mathrm{AOR}=1.03,95 \% \mathrm{CI} 0.63-1.68 ; \mathrm{AOR}=1.07,95 \%$ CI 0.52-2.22, respectively). Conclusion. Lower maternal sensitivity, measured by direct observation of parent-adolescent interactions, was associated with adolescent obesity. Efforts to prevent and treat childhood obesity, both at the practitioner level and the community level, may be enhanced by educating parents that their reactions to their children's behaviors may have consequences related to obesity.
\end{abstract}

Keywords: Adolescent, father, mother, obesity, parenting

Abbreviations: NICHD SECCYD, National Institute of Child Health and Human Development Study of Early Child Care and Youth Development; ITNR, income-to-needs ratio

\section{Introduction}

The epidemic of childhood obesity has been well documented, with the Centers for Disease Control reporting that $18.1 \%$ of US adolescents are obese (1). Understanding potentially modifiable factors is imperative to develop successful prevention and intervention programs for childhood obesity.

Experts have long recognized the importance of parenting in relation to childhood obesity (2-5).
Several recent studies have identified specific parenting styles, operationalized on dimensions of parental sensitivity and expectations of child self-control, as associated with childhood obesity (6-11). In general, authoritative parenting style (high sensitivity and high demands for self-control) has been associated with a lower prevalence of childhood obesity when compared to permissive (high sensitivity and low demands for self-control), authoritarian (low

Correspondence: Dr Roy Neal Davis, MD MS, Intermountain Healthcare, Pediatrics, 5063 S. Cottonwood Street, Suite 160 Murray, UT 84107, USA. Tel: +1 801507 1839. Fax: +1 801507 1850. Email: Neal.Davis@imail.org 
sensitivity and high demands for self-control), and neglectful (low sensitivity and low demands for self-control) parenting styles.

Rhee et al., using the National Institute of Child Health and Human Development Study of Early Child Care and Youth Development (NICHD SECCYD), found that low maternal sensitivity, measured by direct observation of mother-child interactions, was associated with increased odds of childhood obesity in first grade (8). They also found that mothers with an authoritative parenting style were less likely to have obese children compared to mothers with other parenting styles. Some subsequent studies confirmed this association between parenting style and childhood obesity $(6,9-12)$, while other studies failed to find this association $(13,14)$. These mixed findings may, in part, reflect the varying methods that were used to measure parenting style. To date, the study by Rhee et al. is the only study to use direct observation of parent-child interactions to operationalize parenting style.

While many studies of parenting style and childhood obesity have focused on young children $(8,12-$ 14) or may have included adolescents as part of their sample (9), few have focused on adolescents. The dearth of research with adolescent samples is particularly important given that the likelihood of obesity continuing into adulthood increases in adolescence $(15,16)$ and many of the health risks related to obesity emerge in adolescence $(17,18)$. In addition, parenting behaviors, in general, are less strongly associated with outcomes as children grow older and parent-child relationships become increasingly complex (19). Therefore, findings in younger cohorts may not be applicable to adolescents. Just three recent studies have focused exclusively on adolescents, with two of the studies coming from the same data source $(10,11)$. In the first study, Kim et al., using survey data from 106 adolescents, found that maternal, but not paternal, authoritative parenting style was associated with lower adolescent body mass index (BMI) (10). In the second two studies using data from Project EAT (Eating Among Teens), Berge et al. reported survey data from 4,746 adolescents cross-sectionally (6) as well as follow-up survey data from 2516 of these adolescents 5 years later (11). They found in both studies that maternal, but not paternal authoritative parenting style was associated with lower adolescent BMI. These studies used adolescent report survey data to inform our understanding of how parenting style is implicated in obesity during adolescence. The use of standardized observed measures for parenting style during adolescence may provide confirmation and further insights into the relationship between adolescent obesity and parenting style.
Paternal parenting style has not been routinely included in studies regarding childhood obesity. As mentioned above, Kim et al. and Berge et al. both found that paternal parenting style was not independently associated with adolescent obesity. In contrast, Wake et al. (12), using parent survey data of 3040 Australian children ages 4-5 years, found that permissive and neglectful paternal parenting styles were associated with increased odds of childhood overweight and obesity. As such, the relationship between paternal parenting and obesity risk may be moderated by demographic factors or source of parentingstyle data. Specifically, the association identified by Wake et al. was in a cohort that was significantly younger, as compared to the cohort in Berge et al. The Wake et al. cohort was also Australian compared to Berge's racially diverse US cohort. The role of fathers may differ across these demographics. In addition, parenting style in Wake et al. was based on parent self-report, while parenting style in Berge et al. was based on adolescent report. Further investigation of paternal parenting style in association with childhood obesity risk using an adolescent cohort in which parenting style is measured using objective observation may help to clarify how paternal parenting is implicated in obesity during adolescence.

It may also be useful to go beyond the traditional classification of parenting style used in studies with younger children. Parental monitoring has received increased attention in studies of adolescent well being and has been associated with improved adolescent health behaviors, such as less substance use and fewer sexual risk behaviors (20-22). However, only one study has examined parental monitoring in an exclusively adolescent sample related to obesity (23). Lee et al. found that obese adolescents with less parental monitoring (not having a curfew set by their parents) were at increased risk of remaining obese as they transitioned into adulthood (23). Given the fundamental transition to increased autonomy in parent-child relationships during adolescence, use of parental monitoring as a dimension of parenting style, instead of demands for self-control, may be more relevant for adolescent obesity.

Further understanding of the association between parenting style and adolescent obesity could inform the development of more effective prevention and intervention programs. Our study had three hypotheses: (i) The association between lower sensitivity and childhood obesity, identified by Rhee et al., will persist in the same NICHD SECCYD cohort during adolescence; (ii) less parental monitoring will be associated with adolescent obesity; and (iii) in this primarily middle-income US cohort, these associations will be true for both maternal and paternal parenting. 


\section{Methods}

We used data from the NICHD SECCYD, a longitudinal cohort which began at the time of the child's birth in 1991 with the enrollment of 1364 families at 10 sites across the United States. Details of study design and recruitment procedures are available at https://secc.rti.org (24). The study was approved by the institutional review boards of all relevant institutions.

\section{Measures}

\section{Dependent variable}

Height and weight were measured at age $15 \frac{1}{2}$ years using a standardized protocol (25). BMI was calculated and percentiles derived from the US Centers for Disease Control growth curves (26). Obesity was defined as a BMI $\geq 95$ th percentile for age and sex.

\section{Independent variables}

Maternal and paternal sensitivity were assessed by a standardized videotaped interaction task, developed for this study, and conducted in the adolescent's home at age 15 years. The interaction task was based on work by Allen et al. (27) and consisted of an 8-minute timed discussion between the adolescent and the mother or father regarding one or more (typically two) areas of conflict. Adolescents were shown a list of possible topics (e.g., homework, chores, or use of free time) and asked to select two main topics of disagreement with their mother or father. Adolescents could choose the same topics for discussion with each parent or could choose different topics for their mother and father. Adolescents discussed the topics separately with mothers or fathers after other family members and members of the research team left the room. In households with a mother and father, interaction tasks were done on the same day, with the mother interaction task always done first.

Coding for maternal and paternal sensitivity was based on coding systems used for interaction tasks conducted during earlier waves of the NICHD SECCYD, as well as the Autonomy and Relatedness Coding System and the Supportiveness Behavior Task Coding System (28). Mothers and fathers were rated by trained and reliable coders on a 7-point scale from "very low" to "very high" in six different subscales: Validation, engagement, inhibiting relatedness, hostility, respect for autonomy, and warmth. Scores for inhibiting relatedness and hostility were reverse coded. Cronbach's alpha for these six subscales was
0.81 for mothers and 0.79 for fathers (29). Subscale scores were summed to create a composite sensitivity score with a potential range of 6-42, with higher scores reflecting greater observed sensitivity. We sought to create a dichotomous score for sensitivity. Given the characteristics of this sample, in which most parents were relatively sensitive, we sought to differentiate parents who were lower in sensitivity. We therefore dichotomized sensitivity scores such that the lowest quartile was considered "lower sensitivity" (9-28 for mothers and 10-29 for fathers), and the higher three quartiles "higher sensitivity" (29-42 for mothers and 30-42 for fathers).

Parental monitoring was assessed by an 11-item questionnaire that was developed for the NICHD SECCYD and administered separately to mothers and fathers (29). The questionnaire focused primarily on parental knowledge of adolescent activities with some questions on parental supervision of activities (21). Parents responded on a 4-point Likert scale to each item (see Appendix A). Cronbach's alpha was 0.77 for maternal monitoring and 0.84 for paternal monitoring (29). An average monitoring score across the 11 items was calculated with a range of 1-4, with higher scores reflecting higher monitoring. As was done with the sensitivity scores, we dichotomized monitoring scores such that the lowest quartile was considered "lower monitoring" (2.09-3.36 for mothers and 1.30-3.09 for fathers), and the higher three quartiles "higher monitoring" (3.40-4.00 for mothers and 3.18-4.00 for fathers).

\section{Covariates}

We included parental obesity as a covariate given its strong association with childhood obesity (16). When the children were 15 years old, mothers reported height and weight for themselves and the adolescent's biological father. BMI was calculated and obesity defined as $\mathrm{BMI} \geq 30$. We had a significant amount of missing data for parental BMI ( $9 \%$ for mothers and $32 \%$ for fathers). We created variables for maternal and paternal obesity in the categories of obese, not obese, and obesity status unknown. This allowed us to include maternal and paternal BMI information if available in all analyses without substantially limiting our sample size for missing data. We included household income-to-needs ratio (ITNR; total household income divided by the household income of a family of the same size at the federal poverty line) as a continuous variable, because lower household income has been associated with a higher prevalence of adolescent obesity (30). We included adolescent sex and race/ethnicity as covariates due to their interactive associations with adolescent obesity (31). 
Table I. Sample characteristics by adolescent obesity status $(n=744)$.

\begin{tabular}{|c|c|c|c|c|}
\hline & Total sample, $n(\%)$ & $\begin{array}{l}\text { Adolescent obese } \\
\text { at } 15 \mathrm{yr}, n(\%)\end{array}$ & $\begin{array}{c}\text { Adolescent not obese } \\
\text { at } 15 \mathrm{yr}, n(\%)\end{array}$ & $p$-value \\
\hline \multicolumn{5}{|l|}{ Adolescent sex } \\
\hline Male & $373(50.13)$ & $60(56.07)$ & $313(49.14)$ & 0.184 \\
\hline Female & $371(49.87)$ & $47(43.93)$ & $324(50.86)$ & \\
\hline Adolescent race & & & & 0.067 \\
\hline White & $610(81.99)$ & $81(75.70)$ & $529(83.05)$ & \\
\hline Not white & $134(18.01)$ & $26(24.30)$ & $108(16.95)$ & \\
\hline Maternal obesity, $\mathrm{BMI} \geq 30$ & & & & $<0.001$ \\
\hline Mother obese & $188(25.27)$ & $62(57.94)$ & $126(19.78)$ & \\
\hline Mother not obese & $511(68.68)$ & $42(39.25)$ & $469(73.63)$ & \\
\hline Mother obesity status unknown & $45(6.05)$ & $3(2.80)$ & $42(6.59)$ & \\
\hline Paternal, BMI $\geq 30$ & & & & $<0.001$ \\
\hline Father obese & $137(18.41)$ & $28(26.17)$ & $109(17.11)$ & \\
\hline Father not obese & $392(52.69)$ & $34(31.78)$ & $358(56.20)$ & \\
\hline Father obesity status unknown & $215(28.90)$ & $45(42.06)$ & $170(26.69)$ & \\
\hline Household income-to-needs ratio, mean (SD) & $5.22(5.78)$ & $3.01(2.45)$ & $5.60(6.08)$ & $<0.001$ \\
\hline
\end{tabular}

\section{Statistical analyses}

Of 1364 children enrolled at birth, 844 had height and weight measured at $15^{1 / 2}$ years. Of these, 744 had data for maternal or paternal parenting measures and all covariates (Table I). 709 adolescents had complete data for maternal sensitivity and monitoring with other covariates. 460 had complete data for paternal sensitivity and monitoring with other covariates. Those without complete maternal data were more likely to be non-white and to have a lower ITNR. Those without complete paternal data were more likely to be obese, non-white, and have a lower ITNR. Those without complete data did not differ regarding measures of parental sensitivity and monitoring.

We used multivariate logistic regression to evaluate associations of maternal and paternal sensitivity and monitoring with adolescent obesity. We created two separate models, one using maternal parenting measures $(n=709$ per above) and the other using paternal parenting measures ( $n=460$ per above). Each model was adjusted for the covariates maternal and paternal obesity, family ITNR, and adolescent race and sex. In each of these models (maternal and paternal), we tested for interactions between parental sensitivity and monitoring, parental sensitivity and child sex, and parental monitoring and child sex. All analyses were performed with SAS 9.2.

\section{Results}

Characteristics of the sample by adolescent obesity status are shown in Table I. Of the 744 adolescents in our sample, $49.9 \%$ were female, $82.0 \%$ were white, and $14.4 \%$ were obese. The average household ITNR for the sample was 5.2 reflecting a largely middle to upper income sample. A total of $25.3 \%$ of adolescents had an obese mother and $18.4 \%$ had an obese father. Obese, compared to non-obese adolescents, were more likely to live in a household with a lower ITNR,

Table II. Maternal and paternal parenting measures by adolescent obesity status.

\begin{tabular}{|c|c|c|c|c|}
\hline & Total sample & $\begin{array}{l}\text { Adolescent } \\
\text { obese at } 15 \mathrm{yr}\end{array}$ & $\begin{array}{l}\text { Adolescent not } \\
\text { obese at } 15 \mathrm{yr}\end{array}$ & $p$-value \\
\hline \multicolumn{5}{|l|}{ Maternal sensitivity $(n=709)^{*}$} \\
\hline Lower: $\leq 25$ th percentile & $164(23.13)$ & $41(39.05)$ & $123(20.36)$ & \multirow[t]{2}{*}{$<0.0001$} \\
\hline Higher: $>25$ th percentile & $545(76.87)$ & $64(60.95)$ & $481(79.64)$ & \\
\hline \multicolumn{5}{|c|}{ Maternal monitoring $(n=709)^{*}$} \\
\hline Lower: $\leq 25$ th percentile & $203(28.63)$ & $35(33.33)$ & $168(27.81)$ & \multirow[t]{2}{*}{0.248} \\
\hline Higher: $>25$ th percentile & $506(71.37)$ & $70(66.67)$ & $436(72.19)$ & \\
\hline \multicolumn{5}{|l|}{ Paternal sensitivity $(n=460)^{\dagger}$} \\
\hline Lower: $\leq 25$ th percentile & $121(26.30)$ & $13(24.53)$ & $108(26.54)$ & \multirow[t]{2}{*}{0.755} \\
\hline Higher: $>25$ th percentile & $339(73.70)$ & $40(75.47)$ & $229(73.46)$ & \\
\hline \multicolumn{5}{|l|}{ Paternal monitoring $(n=460)^{\dagger}$} \\
\hline Lower: $\leq 25$ th percentile & $113(24.57)$ & $13(24.23)$ & $100(24.57)$ & \multirow[t]{2}{*}{0.995} \\
\hline Higher: $>25$ th percentile & $347(75.43)$ & $40(75.47)$ & $307(75.43)$ & \\
\hline
\end{tabular}

${ }^{*} n=709$ with complete maternal data; ${ }^{\dagger} n=460$ with complete paternal data. 
Adolescent obesity and parenting style e461

Table III. Adjusted Odds Ratios (AOR) of adolescent obesity by maternal and paternal parenting predictors.

\begin{tabular}{|c|c|c|c|}
\hline & $\begin{array}{l}\text { Adjusted odds of } \\
\text { adolescent obesity by } \\
\text { maternal parenting } \\
\text { predictors, } n=709\end{array}$ & $\begin{array}{c}\text { Adjusted odds of adolescent } \\
\text { obesity by paternal } \\
\text { parenting predictors, } \\
n=460\end{array}$ & $\begin{array}{c}\text { Adjusted odds of adolescent } \\
\text { obesity by maternal and } \\
\text { paternal parenting } \\
\text { predictors, } n=460\end{array}$ \\
\hline & $\operatorname{AOR}(95 \% \mathrm{CI})$ & AOR $(95 \% \mathrm{CI})$ & $\operatorname{AOR}(95 \% \mathrm{CI})$ \\
\hline Lower maternal sensitivity ${ }^{\mathrm{a}}$ & $2.36(1.44-3.86)$ & - & $2.06(0.99-4.28)$ \\
\hline Lower maternal monitoring ${ }^{\mathrm{b}}$ & $1.03(0.63-1.68)$ & - & $0.67(0.31-1.45)$ \\
\hline Lower paternal sensitivity ${ }^{\mathrm{a}}$ & - & $0.79(0.38-1.63)$ & $0.65(0.30-1.40)$ \\
\hline Lower paternal monitoring ${ }^{b}$ & - & $1.07(0.52-2.22)$ & $1.10(0.51-2.34)$ \\
\hline Adolescent male ${ }^{c}$ & $1.45(0.91-2.29)$ & $2.27(1.18-4.37)$ & $2.30(1.17-4.49)$ \\
\hline Adolescent Race/Ethnicity non-white ${ }^{\mathrm{d}}$ & $1.21(0.68-2.18)$ & $0.80(0.33-1.95)$ & $0.77(0.30-1.94)$ \\
\hline Household income-to-needs ratio & $0.86(0.77-0.95)$ & $0.87(0.77-0.99)$ & $0.88(0.77-1.00)$ \\
\hline Mother obese $\mathrm{e}^{\mathrm{e}}$ & $4.46(2.79-7.15)$ & $5.11(2.61-10.0)$ & $5.17(2.60-10.3)$ \\
\hline Mother obesity status Unknown ${ }^{\mathrm{e}}$ & $0.45(0.10-2.07)$ & $0.56(0.12-2.61)$ & $0.75(0.13-4.47)$ \\
\hline Father obese $\mathrm{f}^{\mathrm{s}}$ & $2.03(1.11-3.69)$ & $2.10(1.08-4.08)$ & $1.96(0.99-3.88)$ \\
\hline Father obesity status Unknown ${ }^{\mathrm{f}}$ & $2.02(1.17-3.50)$ & $3.04(0.75-12.3)$ & $2.63(0.59-11.8)$ \\
\hline
\end{tabular}

${ }^{a}$ Reference is higher sensitivity; ${ }^{b}$ Reference is higher monitoring; ${ }^{c}$ Reference is adolescent female; ${ }^{d}$ Reference is white race/ethnicity; ${ }^{\mathrm{e}}$ Reference is mother not obese; ${ }^{\mathrm{f}}$ Reference is father not obese.

to have an obese mother, and to have obese father (Table I).

Maternal and paternal parenting measures are shown by adolescent obesity status in Table II. Obese, compared to non-obese adolescents, were more likely to have mothers with lower sensitivity. There were no differences in paternal sensitivity or maternal and paternal monitoring by adolescent obesity in unadjusted analyses.

The adjusted models for maternal sensitivity and monitoring predicting adolescent obesity and paternal sensitivity and monitoring predicting adolescent obesity are shown in Table III. Lower maternal sensitivity, but not lower maternal monitoring, was independently associated with increased risk of adolescent obesity. Neither lower paternal sensitivity nor lower paternal monitoring was independently associated with adolescent obesity. Within each (maternal and paternal) model, there were also no significant interactions between sensitivity and monitoring (maternal sensitivity $\times$ maternal monitoring, $p=0.75$; paternal sensitivity $\times$ paternal monitoring, $p=0.52$ ), sensitivity and child sex (maternal sensitivity $\times$ child sex, $p=0.63$; paternal sensitivity $\times$ child $\operatorname{sex}, p=0.28$ ), or monitoring and child sex (maternal monitoring $\times$ child sex, $p=0.75$; paternal monitoring $\times$ child sex, $p=0.67$ ).

Finally, in a combined model including both maternal and paternal parenting measures $(n=425)$, we found that the relationship between maternal sensitivity and adolescent obesity persisted, though did not reach statistical significance in this smaller sample (Table III). Paternal sensitivity and maternal and paternal monitoring, again, were not associated with adolescent obesity. However, maternal obesity and adolescent male sex were associated with adolescent obesity.

\section{Discussion and conclusion}

To our knowledge, this is the first study to use direct observation of parent-adolescent interactions to evaluate associations between the parenting styles of mothers and fathers and adolescent obesity. We found that lower maternal sensitivity was independently associated with adolescent obesity. These results from the adolescent wave of the NICHD SECCYD are consistent with Rhee et al.'s findings regarding maternal sensitivity and childhood obesity in the same NICHD SECCYD cohort at a younger age (8). In addition, this study supports findings reported by Berge et al. and Kim et al. $(6,10,11)$ that lower maternal, but not paternal, sensitivity is associated with adolescent obesity, by using direct observation of the mother-adolescent interactions.

The association between parenting style and childhood obesity may be explained, in part, by dysregulation of eating habits in children $(2,8)$. Lower sensitivity has been associated with pressuring children to eat (32), increased adolescent intake of sugar sweetened beverages (33), and lower adolescent fruit intake (34). Lower maternal sensitivity has also been associated with decreased physical activity and increased sedentary behavior in adolescents (34), as well as decreased ability of children to regulate their response to negative experiences (35). Given emerging data associating obesity with adverse life stresses (36), lower maternal sensitivity may leave adolescents particularly vulnerable to many of the transitions and increased life stresses characteristic of adolescence. Finally, lower maternal sensitivity may, in and of itself, be a chronic stressor for children and adolescents that impacts metabolism and appetite regulation through the hypothalamic-pituitary-adrenal axis (37). More research is needed to further examine possible 
mechanisms of this association and its continued presence in adolescence.

We did not find associations between paternal sensitivity and adolescent obesity in bivariate or multivariate analyses. This is consistent with the findings of Berge et al. and Kim et al. $(6,10,11)$, but supports the findings by direct observation of parenting style in a large sample that is relatively middle-income, in whom one might have predicted a more integral role of fathers in parenting. Though the findings suggest that maternal sensitivity is more strongly implicated in adolescent obesity than paternal sensitivity, the results must be interpreted with caution. For example, there may be other aspects of the behavior of fathers that are relevant to adolescent obesity and were not examined. For example, Berge et al. reported that adolescent girls in their sample had higher BMI if their fathers did not model or encourage healthy eating and physical activity (6). In addition, all of the fathers in our sample were required to actively engage in the study and, therefore, may be different than fathers in the general population. As such, though our study indicates that lower sensitivity within this group of relatively engaged fathers did not predict adolescent obesity, the possibility remains that the lower sensitivity among less engaged fathers might be predictive of adolescent obesity. Finally, given that fathers are playing an increasing caretaking role in many families (38), further evaluation of paternal parenting style and adolescent obesity may be needed in the future.

Contrary to our hypothesis, we did not find any associations between maternal or paternal monitoring of adolescent activities and adolescent obesity. In part, this may be due to our measure of parental monitoring largely reflecting parental knowledge of adolescent activities, as opposed to parental monitoring defined by actually having and enforcing rules around the adolescent's activities. Parental knowledge of adolescent activity alone has been critiqued as an inadequate measure of parental monitoring (39). Indeed, in a study of children aged 8-16, Zeller et al. found that obese children were less likely to have parents who established rules and consistently enforced them (9). Finally, parental monitoring measures may need to be focused specifically on factors related to eating behaviors and actual food consumption to impact child and adolescent obesity.

Our study had several limitations. First, we used a cross-sectional design and, therefore, are limited in our ability to infer causality. We hypothesize that lower maternal sensitivity may contribute to adolescent obesity; however, it is also possible that some mothers treat obese adolescents with less sensitivity. Second, the sample size in our paternal model and combined model may have limited our ability to detect potential differences. Finally, because the study was observational, we cannot exclude the possibility of the associations being due to unmeasured confounding variables.

In conclusion, lower maternal sensitivity, measured by direct observation of parent-adolescent interactions, was associated with adolescent obesity. Future research is needed to understand possible mechanisms for this association. Pediatric providers should recognize the role of sensitive parenting as potentially protective against childhood obesity, not only for young children, but also for adolescents. Efforts to prevent and treat childhood obesity, both at the practitioner level and the community level, may be enhanced by educating parents that their reactions to their children's behaviors may have consequences related to obesity.

\section{Acknowledgements}

R. Neal Davis was supported by a training grant from the National Institute of Child Health and Human Development (T32 HD07534). This work was supported in part by an American Heart Association Midwest Affiliate Grant-in-Aid 0750206Z to Dr Lumeng. We acknowledge Kyung E. Rhee, MD, $\mathrm{MSc}$, for her assistance in editing this manuscript.

Declaration of interest: The authors report no conflicts of interest. The authors alone are responsible for the content and writing of the paper.

\section{References}

1. Ogden CL, Carroll MD, Curtin LR, Lamb MM, Flegal KM. Prevalence of High Body Mass Index in US children and adolescents, 2007-2008. JAMA. 2010;303(3):242-9.

2. Rhee K. Childhood overweight and the relationship between parent behaviors, parenting style and family functioning. Ann Am Acad Polit SS. 2008;615:12-37.

3. Epstein LH, Valoski A, Wing RR, McCurley J. Ten-year outcomes of behavioral family-based treatment for childhood obesity. Health Psychol. 1994;13(5):373-83.

4. Golan M, Crow S. Parents are key players in the prevention and treatment of weight-related problems. Nutr Rev. 2004; $62(1): 39-50$

5. Lindsay AC, Sussner KM, Kim J, Gortmaker S. The role of parents in preventing childhood obesity. Future Child. 2006;16(1):169-86.

6. Berge JM, Wall M, Bauer KW, Neumark-Sztainer D. Parenting characteristics in the home environment and adolescent overweight: A latent class analysis. Obesity. 2009;18(4): 818-25.

7. Maccoby E, Martin J. Socialization in the context of the family: parent-child interaction. In: Hetherington E, editor. Handbook of Child Psychology: Socialization, Personality and Social Development. New York: Wiley; 1983. p. $1-101$.

8. Rhee KE, Lumeng JC, Appugliese DP, Kaciroti N, Bradley RH. Parenting styles and overweight status in first grade. Pediatrics. 2006;117(6):2047-54 
9. Zeller MH, Boles RE, Reiter-Purtill J. The additive and interactive effects of parenting style and temperament in obese youth seeking treatment. Int J Obesity (Lond). 2008; 32(10):1474-80.

10. Kim MJ, McIntosh WA, Anding J, Kubena KS, Reed DB, Moon GS. Perceived parenting behaviours predict young adolescents' nutritional intake and body fatness. Matern Child Nutr. 2008;4(4):287-303.

11. Berge JM, Wall M, Loth K, Neumark-Sztainer D. Parenting style as a predictor of adolescent weight and weight-related behaviors. J Adol Health. 2010;46(4):331-8.

12. Wake $M$, Nicholson JM, Hardy P, Smith K. Preschooler obesity and parenting styles of mothers and fathers: Australian National Population Study. Pediatrics. 2007;120(6): E1520-7.

13. Agras WS, Hammer LD, McNicholas F, Kraemer HC. Risk factors for childhood overweight: a prospective study from birth to 9.5 years. J Pediatr. 2004;145(1):20-5.

14. Gable S, Lutz S. Household, parent, and child contributions to childhood obesity. In: Kansas City, Missouri: National Council Family Relations; 1998. pp. 293-300.

15. Nader PR, O'Brien M, Houts R. Identifying risk for obesity in early childhood. Pediatrics. 2006;118(3): e594-601.

16. Whitaker RC, Wright JA, Pepe MS, Seidel KD, Dietz WH. Predicting obesity in young adulthood from childhood and parental obesity. New Engl J Med. 1997:869-73.

17. Weiss R, Dziura J, Burgert TS, et al. Obesity and the metabolic syndrome in children and adolescents. New Engl J Med. 2004;350(23):2362-74.

18. Sinha R, Fisch G, Teague B, et al. Prevalence of impaired glucose tolerance among children and adolescents with marked obesity. New Engl J Med. 2002;346(11):802-10.

19. Hill NE, Bromell L, Tyson F, Flint R. Developmental commentary: ecological perspectives on parental influences during adolescence. J Clin Child Adolesc. 2007;36(3):367-77.

20. Hoeve M, Dubas JS, Eichelsheim VI, van der Laan PH, Smeenk W, Gerris JRM. The relationship between parenting and delinquency: a meta-analysis. J Abnorm Child Psychol. 2009;37(6):749-75.

21. Dishion TJ, McMahon RJ. Parental monitoring and the prevention of child and adolescent problem behavior: a conceptual and empirical formulation. Clin Child Fam Psychol Rev. 1998;1(1):61-75.

22. DeVore ER, Ginsburg KR. The protective effects of good parenting on adolescents. Curr Opin Pediatr. 2005;17(4): 460-5.

23. Lee H, Harris KM, Gordon-Larsen P. Life course perspectives on the links between poverty and obesity during the transition to young adulthood. Popul Res Policy Rev. 2009; 28:505-32.

24. The National Institute of Child Health and Human Development Study of Early Childhood Care and Youth Development. Study summary. Available at: http://secc.rti.org/ summary.cfm. Accessed 13 Oct 2009.

25. National Institute of Child Health and Human Development Study of Early Childhood Care and Youth Development. Operations Manual: Health and Physical Development Assessment (HPDA) Visit. Available at: https://secc.rti.org/display. $\mathrm{cfm} ? \mathrm{t}=\mathrm{m} \& \mathrm{i}=$ Chapter_85_1. Accessed 7 Aug 2009.

\section{Supplementary Material Available Online}

\section{Appendix A}

26. Centers for Disease Control and Prevention. CDC Growth Charts. http://www.cdc.gov/growthcharts/clinical_charts.htm. Accessed 15 Dec 2009.

27. Allen JP, Hauser ST, Bell KL, O'Connor TG. Longitudinal assessment of autonomy and relatedness in adolescent-family interactions as predictors of adolescent ego development and self-esteem. Child Dev. 1994;65(1):179-94.

28. Owen MT, Klausli J, Aultman C, Brown G, Little I, Milling L. National Institute of Child Health and Human Development Study of Early Childhood Care and Youth Development, Age 15 Parent-Adolescent Interaction Task: Addendum D, Age 15 Parent-Adolescent Interaction Coding System. Available at: https://secc.rti.org/display. $\mathrm{cfm} ? \mathrm{t}=\mathrm{m} \& \mathrm{i}=$ Chapter_91_05. Accessed 11 Aug 2009.

29. National Institute of Child Health and Human Development Study of Early Childhood Care and Youth Development. Phase IV Instrument Documentation. Available at: https://secc.rti.org/Phase4InstrumentDoc.pdf. Accessed 8 Aug 2009.

30. Miech RA, Kumanyika SK, Stettler N, Link BG, Phelan JC, Chang VW. Trends in the association of poverty with overweight among US adolescents, 1971-2004. JAMA. 2006; 295(20):2385-93.

31. Ogden CL, Carroll MD, Curtin LR, McDowell MA, Tabak CJ, Flegal KM. Prevalence of overweight and obesity in the United States, 1999-2004. JAMA. 2006;295(13): 1549-55.

32. Hubbs-Tait L, Kennedy TS, Page MC, Topham GL, Harrist AW. Parental feeding practices predict authoritative, authoritarian, and permissive parenting styles. J Am Diet Assoc. 2008;108(7):1154-61.

33. van der Horst K, Kremers S, Ferreira I, Singh A, Oenema A, Brug J. Perceived parenting style and practices and the consumption of sugar-sweetened beverages by adolescents. Health Educ Res. 2007;22(2):295-304.

34. Schmitz KH, Lytle LA, Phillips GA, Murray DM, Birnbaum AS, Kubik MY. Psychosocial correlates of physical activity and sedentary leisure habits in young adolescents: The teens eating for energy and nutrition at school study. Prev Med. 2002;34(2):266-78.

35. Denham SA, Workman E, Cole PM, Weissbrod C, Kendziora KT, Zahn-Waxler C. Prediction of externalizing behavior problems from early to middle childhood: the role of parental socialization and emotion expression. Dev Psychopathol. 2000;12(1):23-45.

36. Vamosi M, Heitmann BL, Kyvik KO. The relation between an adverse psychological and social environment in childhood and the development of adult obesity: a systematic literature review. Obes Rev. 11(3):177-84.

37. Dallman MF. Stress-induced obesity and the emotional nervous system. Trends Endocrinol Metab. 2009; 21(3):159-65.

38. Pleck J, Masciadrelli B. Paternal involvement by U.S. residential fathers: Levels, sources, and consequences. In: Lamb M, editor. The Role of the Father in Child Development. 4th ed. Hoboken, NJ: Wiley; 2004.

39. Ellis DA, Templin TN, Naar-King S, Frey MA. Toward conceptual clarity in a critical parenting construct: parental monitoring in youth with chronic illness. J Pediatr Psychol. 2008;33(8):799-808. 